\title{
PEDAGOGIA CRÍTICA DA EDUCAÇÃO FÍSICA: DILEMAS E DESAFIOS NA ATUALIDADE
}

\author{
CRITICAL PEDAGOGY IN PHYSICAL EDUCATION: CONTEMPORARY \\ DILEMMAS AND CHALLENGES
}

PEDAGOGÍA CRÍTICA DE LA EDUCACIÓN FÍSICA: DILEMAS Y DESAFÍOS EN LA ACTUALIDAD

Valter Bracht*, Felipe Quintão de Almeida*

Palavras chave: Educação Física. Ensino. Linguagem. Corpo.
Resumo: Este artigo objetiva discutir alguns dilemas e desafios da pedagogia crítica da Educação Física, considerando, para tanto, a paisagem cognitiva e política contemporânea. Assim o faz a partir da eleição de três temas condutores. O primeiro deles discute o status da própria noção de crítica e seus reflexos no plano social e epistemológico. O segundo problematiza as condições da normatividade no âmbito da pedagogia crítica. $O$ último deles reflete sobre o "dilema culturalista" das perspectivas críticas em Educação Física, representado pelo "problema da articulação" entre a linguagem e o corpo.
Keywords: Physical Education. Teaching. Language. Body.

Palabras clave: Educación Física. Enseñanza. Lenguaje. Cuerpo.
Abstract: The aim of this paper is to discuss some dilemmas and challenges in critical pedagogy for Physical Education regarding the contemporary cognitive and political landscape. Three main themes organise our discussion. The first one is the status of the notion of "critical" and its possible effects in the social and epistemological sphere. The second topic problematizes the conditions of the normative knowledge in critical pedagogy. The last theme provides a reflection on the "cultural dilemma" of the critical perspectives in Physical Education, represented by the "problem of articulation" between language and body.
Resumen: Este artículo tiene por objetivo discutir algunos dilemas y desafíos de la pedagogía crítica de la Educación Física, considerando, para esto, el paisaje cognitivo y político contemporáneo. Se desarrolla a partir de tres temas conductores. El primero discute el status de la propia noción de crítica y sus reflejos en el plano social y epistemológico. El segundo problematiza las nociones de la normatividad en el plan de la pedagogía crítica. El último reflexiona sobre el "dilema culturalista" de las perspectivas críticas en Educación Física, representado por el "problema de la articulación" entre lenguaje y cuerpo.

*Universidade Federal do Espírito Santo. Vitória, ES, Brasil. E-mail: vbracht13@gmail.com; fqalmeida@ hotmail.com

Recebido em: 10-04-2019 Aprovado em: 03-09-2019 Publicado em: 16-11-2019

DOI: https://doi.org/10.22456/1982-8918.96196 (c) (i) () Licence 


\section{INTRODUÇÃOO}

Neste artigo, em consonância com as motivações que animam o dossiê, discutimos alguns desafios da pedagogia crítica, considerando a paisagem cognitiva atual, designada $\mathrm{e}$ conhecida de muitos modos: pós-moderna, pós-metafísica, pós-fundacional, pós-crítica, póslinguistic turn, etc.

Nosso texto, mais precisamente, está estruturado em torno da problematização de temas que, por um lado, têm indagado a pertinência e a validade das teorias críticas na educação em geral e, por outro, tem desafiado o pensamento pedagógico específico da Educação Física. 0 primeiro deles discute o status da crítica e o de uma pedagogia assim conhecida na atualidade. Será ocasião para, entre outras observações, oferecer um comentário sobre a pedagogia póscrítica, perspectiva educacional bastante influente no Brasil e com repercussões na Educação Física.

O segundo deles analisa as condições da normatividade no âmbito de uma pedagogia crítica. A este respeito, perguntamos: é possível/desejável sustentar seu ideal normativo em tempos pós-metafísicos? Em caso afirmativo, em que bases e/ou circunstâncias afirmá-lo? Apresentaremos duas soluções que se opõem: uma antifundacionista e outra, fundacionista não-representacionista.

O terceiro aspecto discute o "termo ausente" nas perspectivas críticas da Educação Física, com base no que Jans Joas (2002) chamou de "problema da articulação", o que, na área, se manifesta pela necessidade de articular o "discurso sobre o corpo" com um "saber orgânico", para usar a feliz expressão de Betti (1994).

Nossa intenção, com estas problematizações, é menos a de resolver os dilemas intrínsecos a esses desafios, e mais um convite à reflexão na expectativa de renovar e/ou redescrever a tradição crítica da/na área. Cada um dos temas será analisado em tópicos independentes entre si, seguidos das considerações finais.

\section{2 "ESGOTAMENTO” DA CRÍTICA E/OU RENOVAÇÃO DA PEDAGOGIA CRÍTICA?}

Desde os anos 1990, o conceito de pedagogia crítica, no Brasil e no exterior, está em "crise", o que tem exigido esforços em favor da reinvenção de seus fundamentos, mas também da própria definição do que seja ser crítico. Muitas são as razões e as consequências dessa crise para o futuro dessa tradição.

No plano societário mais amplo, por exemplo, temos experimentado uma espécie de trivialização da crítica, o que tem levado à perda de sua efetividade. Para Bauman (2001), a sociedade atual é mais predisposta à crítica do que a de nossos antepassados, pois fez da crítica da "realidade" a expressão "[...] da insatisfação com 'o que aí está' e da expressão dessa insatisfação uma parte inevitável e obrigatória dos afazeres da vida de cada um de seus membros". Apesar dessa sua maior aceitação, prossegue o sociólogo, este tipo de crítica é "desdentada", pois se mostra incapaz de afetar a agenda estabelecida pelo capitalismo contemporâneo, quer dizer, é ineficaz para "[...] alcançar os complexos mecanismos que conectam nossos movimentos com seus resultados e os determinam, e menos ainda as condições que mantêm esses mecanismos em operação" (BAUMAN, 2001, p. 31). 
A crítica não segue mais o modelo de uma "casa compartilhada", com normas e regras institucionalizadas, com atribuição de deveres e desempenho supervisionado. É, doravante, uma crítica ao "estilo do consumidor" e de sua liberdade de consumir. As causas dessa "domesticação" da crítica estão associadas a mudanças na configuração do espaço público, cujo resultado mais evidente é sua invasão pela esfera privada e pela colonização da política pelos poderes extraterritoriais do capital.

Correspondente banalização da crítica também se observa no plano da educação, pois parece que uma formação "crítica" se tornou jargão recorrente em muitas políticas e programas educativos (TINNING, 2010; THIESEN, 2015; LOPES, 2015). Exige-se dos professores que sejam "críticos", reflexivos, pesquisadores, autônomos, inovadores, etc. Este quadro, embora ameaçado por recentes movimentos políticos conservadores na educação brasileira, ${ }^{1}$ nos parece indicar uma funcionalização da crítica, de maneira que aquela ideia do crítico como opositor ao "sistema", à dominação e ao status quo, típica representação do intelectual progressista nos anos 1980, parece útil à ordem quando a oposição entre a liberdade e a crítica, de um lado, e o poder, de outro, já faz parte do modo como a sociedade se organiza (BRACHT, 2016).

No plano epistemológico, o conceito de pedagogia crítica viu-se na necessidade de se defender e, portanto, de se renovar, do advento de uma pedagogia pós-crítica, perspectiva educacional influenciada por tradições teóricas distintas, do pós-modernismo ao pósestruturalismo, passando pelo neopragmatismo, pelos estudos de gênero, culturais, póscoloniais, multiculturalismo, etc. Embora a origem dessa tendência possa ser encontrada no início da década de 1990, quando o campo educacional absorveu intensamente tradições analíticas hoje consideradas "pós", foi no final daqueles anos que o livro de Silva (1999) consolidou, no Brasil, a distinção entre a pedagogia crítica e a pós-crítica. ${ }^{2}$ Seu texto, todavia, é ambíguo em relação à pedagogia crítica, pois ora afirma que não se trata de sua superação, ora assevera que "[...] o pós-modernismo assinala o fim da pedagogia crítica e o começo da pedagogia pós-crítica" (SILVA, 1999, p. 116).

Por algumas razões, reputamos infrutífera essa adjetivação. Se considerarmos a

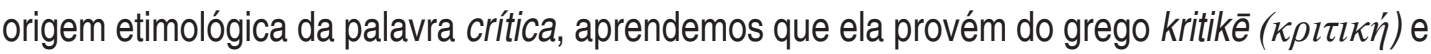
significa "a arte de julgar", de discernir, de decidir, de analisar e de refletir. A crítica é, por assim dizer, a arte da "ruminação vagarosa", a prática com a qual colocamos em questão os limites de nossos modos de conhecimento mais certos por meio do raciocínio permanente. Literalmente, todavia, o prefixo pós indica a ideia de uma etapa posterior, que dispensaria essa "arte de julgar". Este é um efeito certamente não desejado por aqueles que, depois de Silva (1999), assumiram o termo, especialmente porque tal consequência não condiz com a "atitude crítica"3 de autores como Nietzsche, Foucault, Deleuze, Derrida, entre outros, cujas teorias oferecem as ferramentas para justificar o advento da pedagogia pós-crítica. Aliás, esses filósofos não escreveram sobre o tema ou empregaram a expressão pós-crítica para caracterizar seu próprio trabalho. Além disso, como já pontuou Lopes (2013), a expressão pedagogia pós-crítica é vaga e imprecisa, objetivando reunir um conjunto de estudos diferentes, com questões particulares e problemáticas próprias que, não raro, se opõem entre si.

\footnotetext{
1 Por exemplo, o "Escola sem Partido".

2 Embora sem o mesmo impacto verificado no campo educacional mais amplo, os argumentos em favor de uma pedagogia pós-crítica reverberam na Educação Física. No Brasil, é Marcus Garcia Neira seu principal representante. Na literatura anglófona, podemos citar os trabalhos de Bruce $(2013,2015)$. Também lá não parece se configurar como uma tendência deste campo.

3 Empregamos propositadamente essa expressão foucaultiana (1999) para nos referir a certo modo de pensar, de dizer, de agir, a um tipo de relação com o existente, com o que se sabe e com o que se faz, típico, segundo ele, da civilização moderna.
} 
Outro aspecto problemático dessa denominação é o modo estático e homogêneo com que Silva (1999) - e outros depois dele - caracterizou a pedagogia e/ou a tradição crítica. Ele afirma, por exemplo, que para as pedagogias pós-críticas o conhecimento é parte inerente do poder; portanto, não the é exterior nem se opõe a ele, colocando-o em xeque. Com essa avaliação, somos levados a crer que a tradição crítica (e uma pedagogia nela inspirada) desconsiderou o vínculo entre saber e poder. Deste modo, a prática emancipatória seria isenta da vontade de poder; a ciência (conhecimento) seria distinta da ideologia (poder). Neste caso, seria preciso avaliar se essa conclusão se aplica a toda e qualquer tradição crítica. Talvez, no melhor dos casos, a um marxismo ortodoxo, que, é verdade, ainda é vigente em alguns setores da pedagogia crítica (também na Educação Física). Mas, com a leitura, por exemplo, da "Dialética do Esclarecimento", livro "inflexor" no âmbito da teoria crítica de Adorno e Horkheimer (1985), não será difícil concluir que poder e conhecimento são sinônimos ou, se se preferir, que o próprio esclarecimento se converteu em poder político totalitário nas condições da racionalidade instrumental. Em vez de Adorno e Horkheimer, todavia, a pedagogia póscrítica preferiu Foucault (1987), e sua conhecida máxima de que não há relação de poder sem a constituição correlata de um campo de saber, nem conhecimento que não constitua, ao mesmo tempo, relações de poder.

Em outro momento de sua análise, Silva (1999) advoga que as pedagogias críticas limitaram sua análise do poder às relações econômicas do capitalismo, ao passo que, com as pedagogias pós-críticas, o mapa do poder é ampliado para incluir processos de dominação centrados em gênero, etnia, raça e sexualidade. Podemos perguntar, todavia, se essa conclusão se sustenta em relação às teorias críticas que não limitaram suas análises do poder a questões econômicas. Recorrendo, mais uma vez, aos frankfurtianos, ${ }^{4}$ a pergunta que ora fazemos é a seguinte: suas teorias não extrapolaram as questões econômicas na análise do poder? Não poderia ser esta uma das razões pelas quais essa tradição, ao eleger Freud e Nietzsche como interlocutores privilegiados, se distingue do marxismo clássico? Por acaso, a teoria crítica da Escola de Frankfurt não teorizou, na Alemanha hitlerista, sobre questões raciais? E se dissermos que o tema do não-idêntico, ou da diferença (uma das bandeiras da pedagogia pós-crítica) foi um objeto que animou uma parte considerável da filosofia adorniana, particularmente na "Minima Moralia" e na obra "Dialética Negativa"? Ou seja, não há temas tipicamente "pós-críticos" que tenham sido abordados por teóricos críticos? ${ }^{5}$ Não queremos, com isso, sustentar que os argumentos dessa versão da teoria crítica ou de qualquer outra não possam ser criticados nem apontados seus limites. É preciso retomar seus problemas e as questões que ela deixou em aberto. Aliás, herdeiros dessa tradição têm feito isso (ver os trabalhos de Habermas, Welmer e Honneth, entre outros). O problema, aqui, é de outra ordem, mais relacionado ao alcance e/ou ao limite das classificações e/ou aos rótulos em expressar um campo do conhecimento em toda sua complexidade epistemológica, política e metodológica. Qualquer tentativa de caracterizar essa multiplicidade por meio de um conceito aglutinador corre o risco de não a representar em toda a sua extensão.

Alguns colegas da Educação Física, no exterior, assumiram a expressão "big tent" para caracterizar a pluralidade que configura o universo da pedagogia crítica na área. ${ }^{6}$

\footnotetext{
4 "Insistimos" com os "frankfurtianos", pois também constituíram referências importantes na constituição de uma pedagogia crítica, tanto no Brasil como no exterior.

5 Não surpreende algumas análises identificarem similaridades entre a filosofia de Adorno e temas pós-modernos.

6 Consultar, entre outros, Tinning (2010).
} 
Tendências teóricas distintas, como o pós-estruturalismo ou a sociologia de Pierre Bourdieu, são concebidas como parte do território semântico e emancipatório dessa pedagogia. Raça, etnia, gênero, diferença, temas tipicamente "pós", foram incorporados ao discurso crítico, de tal maneira que o pluralismo foi celebrado como uma oportunidade de autocrítica e redescrição da própria pedagogia... crítica. Devis-Devís (2006) chega a dizer, neste contexto, que é difícil precisar a diferença entre pedagogia crítica e outros paradigmas que não se identificam com uma teoria crítica "stricto sensu" (como o pós-estruturalismo), pois estão em constante interação.

No Brasil, malgrado as iniciativas em favor de sua redescrição à luz da irreversível pluralidade, estabeleceu-se uma infrutífera oposição entre os novos referenciais que chegaram ao campo, aqui representada pelo prefixo "pós", e a pedagogia crítica, como se ela própria não fosse capaz de dialogar com outras perspectivas teóricas, políticas e, neste processo, renovarse. ${ }^{7}$ Nessas circunstâncias, talvez seja melhor reconhecer que o campo crítico da Educação e o da Educação Física, em vez de "pós", são mais bem caracterizados por uma pluralidade de perspectivas críticas, o que nos orienta a usar, para ser fiéis a esta condição, a expressão no plural. Nessas áreas, portanto, em vez de uma só, há diferentes versões de pedagogias críticas. Múltiplos, portanto, são os seus objetos, os objetivos que daí derivam e as ferramentas conceituais para a leitura da realidade. Em comum a todas elas, todavia, o comprometimento com a mudança social em favor de um mundo mais justo em termos econômicos, raciais, étnicos, de gênero, etc. ${ }^{8}$

Como último tema deste tópico, a conversa sobre o futuro dessa tradição precisa considerar a mudança de status da própria noção de crítica. É difícil sustentar, na paisagem cognitiva pós-virada linguística, qualquer conotação epistemológica forte e/ou legisladora para o termo (HONNETH, 2009). A crítica não se caracterizaria mais pelo desvelamento da verdade oculta (concepção correspondentista), mas ela foi, por assim dizer, desinflacionada, tornada mais débil, humilde, modesta. Deflacionar a verdade (a crítica, portanto) significa 'dessubstantivá-la' ou 'desessencializá-la', eliminando qualquer resquício de metafísica. Ao se proceder a esse deslocamento, exacerbou-se a dimensão política da noção de crítica.

Nessas condições, talvez seja mesmo possível conciliar diferentes perspectivas epistemológicas da pedagogia crítica sob um único teto ("big tent"), pois a diferença de status entre elas seria mais de ordem retórica e política do que epistemológica. Assim, uma pedagogia crítica inspirada no pós-estruturalismo não é mais "verdadeira" ou mais "substantiva", em termos epistemológicos, do que a que se baseia no marxismo. As dissonâncias entre elas não devem ser medidas em função de sua "aproximação" com o que a realidade é, mas, repetimos, são retóricas e políticas. Umas podem ser mais "complexas", mais difíceis, com mais ou menos floreios argumentativos, com essas ou aquelas estratégias e consequências políticas, mas não podem ser avaliadas em função de sua "correspondência com a realidade". Resta saber, todavia, se essa indecidibilidade do conhecimento inviabiliza (ou não) quaisquer proposições epistêmicas com pretensão de verdade no âmbito da pedagogia crítica, uma discussão que nos remete ao tema seguinte, que trata da normatividade dos fundamentos da pedagogia crítica.

7 Não apenas os advogados da pedagogia pós-crítica foram responsáveis por essa oposição, mas, também, a própria pedagogia marxista, que interpretou a pluralidade teórica e política como modismo, irracionalismo, recuo da teoria, relativismo, etc. (GAMBOA, 2010; TAFFAREL; ALBUQUERQUE, 2010). 


\section{3 (ANTI)FUNDACIONISMO E NORMATIVIDADE... NA PEDAGOGIA CRÍTICA}

Nas condições da hiperpolitização da noção de crítica, um dos desafios que se colocam diz respeito à normatividade do conhecimento (da pedagogia crítica) que se pretende participante da política. Deve a pedagogia crítica fornecer alguma base para 0 agir políticopedagógico? É possível esperar dela algum tipo de fundamento normativo (dever ser) em favor da justiça social (uma de suas principais reinvindicações)? Necessita a pedagogia crítica, conforme Biesta (1998), de padrões, critérios, referências normativas ou de uma utopia, mesmo que seja apenas provisória ou negativa?

Existem algumas maneiras de responder a essas questões. Uma delas pode ser definida como antifundacionista, pois relativiza o papel do conhecimento, inclusive 0 considerado crítico, em oferecer as bases e/ou fundamentos para o agir pedagógico. Embora presente em outras perspectivas que assumiram o discurso pós-crítico e/ou pós-moderno em educação, essa posição veio recentemente à tona com Lopes $(2012,2015)$, ao defender a necessidade de um currículo sem fundamentos, sem um padrão, sem conteúdos básicos ou um conjunto de critérios definidores que possa frear a significação do currículo. Para ela, um currículo com essas características nos remete à constatação de que não há princípios absolutos, definidos por uma teoria científico-pedagógica, por algum princípio racional ou fundamento externo ao jogo político educacional, alheio, portanto, à negociação de sentidos. 0 conteúdo de objetivos como emancipação, justiça social e liberdade não podem ser estabelecidos a priori, mas apenas no âmbito da luta política. Conviver "[...] com a incerteza do jogo político parece ser o que nos resta" (LOPES, 2015, p. 462) se quisermos contribuir com o processo democrático (LOPES, 2012). Influenciada por Laclau (2008), Lopes (2013) argumenta que, nas condições da hiperpolitização, a racionalidade (a verdade, portanto) deve ser politicamente negociada, uma vez que não pode ser logicamente solucionada.

Prossegue a autora (2015) dizendo que um currículo sem fundamentos corresponde à admissão da política em um cenário indefinível, condição que nos obriga a sempre atuar politicamente na expectativa de buscar "[...] dissolver a possibilidade de uma intervenção préprogramada e com projeto de pretensão universalizante, a despeito do jogo político" (LOPES, 2015, p. 461), que é, para ela, caracterizado pela agonística, pelo conflito, pelo acontecimento, "[...] sem definições que nos guiem, sem metas que prescrevam (pré-escrevam, pré-inscrevam) um caminho; só nos cabem o comprometimento e a responsabilidade" (LOPES, 2015, p. 448), em vez da busca de consenso a partir da definição de regras ou metas comuns a todos os contextos. Tais normas serão sempre disputadas e modificados na contextualização radical da política de currículo. A democracia, continua a autora (2012), se ampliará se trabalharmos na direção das múltiplas diferenças, da contingência radical.

Neste âmbito, o papel da teoria (do conhecimento) consistiria não em oferecer fundamentos, mas em questionar o que está estabilizado na política curricular:

Por que pensar desse modo, que é apresentado como única possibilidade, como caminho universalizado e naturalizado, sem que sejam discutidas as condições contextuais que possibilitaram tal proposta? Não se trata de assumir uma posição como certa ou errada criando um novo fundamento, mas tentar entender o que uma dada perspectiva viabiliza e o que bloqueia. Não é uma questão de deve ou não deve, pode ou não pode. Remete à problematização, provocar outras possibilidades de pensar, conceber outras maneiras de objetivar, desestabilizar discursos, sabendo que isso implica estabilizar outros discursos e, portanto, cabe manter aberta a suspeição diante de toda estabilidade (LOPES, 2015, p. 451). 
Outra posição antifundacionista é a de Biesta (1998). Para ele, a ideia de uma pedagogia crítica como programa positivo, como algo que precisa ser implementado, é insustentável, seja porque isso pode resultar numa forma de totalitarismo, seja porque tal programa, assim concebido, pode eventualmente provocar danos à esfera pública, reino da pluralidade, espaço da diferença e da política. $O$ único caminho consistente a que a pedagogia crítica pode recorrer (e, destaca o autor, consistente política e pedagogicamente, não teoricamente) é o de perpetuamente desafiar toda e qualquer reivindicação de autoridade, inclusive a de si própria. Isso implica que tal tarefa não pode ser levada adiante em nome de um conhecimento superior, de uma visão privilegiada ou da posse da verdade, mas deveria fundamentar-se numa falta, quer dizer, no reconhecimento de uma ignorância, que não é sinônimo de inocência ou ceticismo, mas a consciência de não saber como o futuro será ou deveria ser, mas, ainda assim, permanecer na jornada. Ignorância emancipadora, conclui Biesta (1998), pois, em vez de o pedagogo crítico dizer o que pensar sobre algo, pergunta ao outro (seu aluno, por exemplo) o que ele pensa sobre esse algo.

Extrapolando deste raciocínio para a análise da justiça social, tema por excelência da pedagogia crítica, Biesta (1998) defende que a justiça excede a cálculos e a programas. Não se trata de um ideal regulatório, ou de um critério normativo, mas de experiência de um impossível ${ }^{9}$ que não pode ser previsto, que está sempre por vir e sobre o qual não há como decidir ou se decidir. Justiça, por isso, não é problema de uma teoria do conhecimento e de um modo certo de a usar em determinada circunstância, mas remete à capacidade de julgar, que é incalculável. Mas como julgar se não sabemos de antemão o que seja justiça? A pedagogia crítica comprometida com a justiça social deve afirmar esse compromisso, reconhecendo, paradoxalmente, tal impossibilidade. Em outras palavras, a pedagogia crítica precisa reconhecer a impossibilidade da justiça em sua própria busca por justiça. Isto significa, segundo o autor (1998), admitir que a pedagogia crítica não pode previamente saber onde deveria estar a linha divisória do tolerável e do intolerável, do justo e do injusto. Isto requer uma tomada de decisão que, em nome da justiça, não pode esperar, mas ao mesmo tempo "impossível" no sentido de que não tem fundamento prévio.

No nível das práticas, conclui Biesta (1998), a pedagogia crítica não poderia prosseguir dizendo "Isto é o justo, faça como eu faço". A única coisa que ela deveria fazer seria convidar ao julgamento, perguntando: "O que você faria sobre isso"? Esta questão é não-repressiva, no sentido de que ela não prescreve como julgar, mas abre possibilidades ao próprio julgamento.

Estas duas "respostas" antifundacionistas da relação entre conhecimento e normatividade podem ser contrapostas a outra, mais próxima aos nossos próprios aportes teóricos, conhecida como fundacionista não-representacionista. Neste caso, o desafio é fundamentar o caráter normativo do conhecimento da pedagogia crítica sem apelar para um conceito substantivo de verdade ou para a perspectiva do ponto arquimediano, quer dizer, um ponto teórico que seria um critério tão forte que determinaria a explicação de qualquer realidade, seja ela política, moral, educacional ou outra.

Essa concepção compartilha, com a posição anterior, alguns princípios, mas diverge dela em aspectos importantes. Por exemplo, essa orientação ainda defende a necessidade de um vocabulário, representado, neste caso, pela pedagogia crítica, que serviria como referência ou retaguarda crítica às práticas político-educativas ou a um currículo. Isto corresponde a esperar,

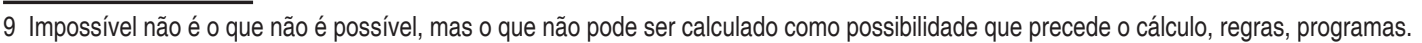


da pedagogia crítica, alguma competência para responder a perguntas fundamentais da vida em comum normativa, em especial da vida política justa. Ela pode, assim, colaborar com os sujeitos nas decisões que precisam assumir em seu dia a dia, orientando-os normativamente, mas sem a pretensão de ser um discurso "extraordinário", superior, porque fundamentado em algum "transcendente" prévio, num programa ou teoria cuja base normativa pressuponha uma leitura mais "correta" do mundo. Ao contrário, a pedagogia crítica está ciente de que sua normatividade não pode ser fundamentada de uma vez por todas ou por uma "correspondência com a realidade", mas por ser autorreferenciada, falibilista e assimilada à afirmabilidade garantida, precisa manter-se discutível e aberta a constante revisão. A noção de crítica que sustenta essa pretensão à normatividade precisa ser coerente com os postulados democráticos e, portanto, com os princípios da pluralidade, da igualdade e da liberdade (BRACHT, 2016).

Além disso, a perspectiva fundacionista não-representacionista ainda vê sentido em estabelecer, nos currículos e programas de ensino, alguns princípios que aspiram ao universal, não se limitando, portanto, às políticas de significação local que dão forma ao currículo. Este universalismo e os conceitos que nele se sustentam (emancipação, justiça, liberdade, etc.) não são decididos a priori, não são absolutos, nem desconsideram o contexto e as interpretações e/ ou traduções que os sujeitos escolares dele realizam, mas resulta dos acordos e/ou consensos a que é possível se chegar no jogo político, que é marcado por diferenças, pluralidade, conflito de ideias e, portanto, pela liberdade. Os acordos obtidos constituem verdades provisórias, processualmente estabelecidas nas práticas de conversação, seu único fundamento.

Em suma, esta perspectiva não-representacionista ainda quer assegurar, em meio à hiperpolitização e à desinflação epistemológica do conceito de verdade, alguma utilidade para o conhecimento que se adjetiva de crítico. As aspirações de verdade e as pretensões de racionalidade proferidas pela pedagogia crítica continuam socialmente relevantes na medida em que suas sentenças são submetidas às críticas de uma ampla comunidade (que inclui professores, pesquisadores, comunidade escolar, etc.), que faz um esforço, sempre incompleto, de identificar e fazer valer os melhores argumentos, o que o qualifica para ser considerado. Mas esse discurso não é superior, nem se opõe a outras discursividades ou formas de conhecimento, mas pode ser um aliado importante na tomada de decisões políticas, sem substituí-las (BRACHT, 2019).

Vale dizer, a pedagogia crítica ainda tem um papel importante para o aprofundamento da democracia, da possibilidade da justiça social (BRACHT, 2019), já que pode atuar não apenas denunciando como algumas pretensões normativas, inclusive as dela própria, podem se converter em práticas que resultam em dominação nos contextos de sua aplicação, como nos alerta Biesta (1998), mas não abre mão de identificar, no âmbito da política democrática, ideais normativos que podem servir de referência para a crítica e a transformação social.

\section{0 "PROBLEMA DA ARTICULAÇÃO" NA PEDAGOGIA CRÍTICA}

Nietzsche (2001) disse que não é eloquente aquilo que "verdadeiramente" nos acontece. Se quiséssemos transmiti-lo, careceríamos de palavras, pois a linguagem foi inventada para informar coisas medíocres, vulgares e comunicáveis, de maneira que, em todos os discursos, há uma espécie de desprezo. Em sua analítica, esse desprezo também nos remete ao corpo, razão pela qual o filósofo alemão procedeu a uma inversão do dualismo que dominou a história 
da Filosofia e que conferiu ao corpo, de Platão a Descartes, a condição decaída do homem, sendo concebido como aquilo que impediria o pensamento, o conhecimento e a verdade. Com Nietzsche, o corpo será uma nova matriz de subjetividade (encarnada, libidinal, pulsional), mas também o ponto de partida de onde a cultura deve começar: "[...] não pela alma (esta foi a superstição funesta dos sacerdotes e semi-sacerdotes), mas pelo corpo, pelos gestos, pelo regime físico, a fisiologia; o resto virá a seu tempo" (NIETZSCHE, 2001, p. 91).

A pedagogia crítica da Educação Física, no Brasil, padeceu da "má-compreensão do corpo" criticada por Nietzsche, pois se fundamentou numa logopoiese, em que consciência e linguagem aparecem desencarnadas. No afã de retirar o corpo da "natureza" e alocá-lo no seio da "cultura", a pedagogia crítica "desprezou" o indizível (a "natureza" do corpo, "aquilo que pode o corpo", segundo a clássica definição spinozana), em favor de um discurso racionalista e/ou culturalista sobre ele. Para tanto, assumiu um linguicentrismo redescritivo para o qual 0 corpo não difere do que dizem dele os discursos imperativos de todos os gêneros que moldam seus movimentos. O corpo, assim, é passivo, substância morta, objeto de alguma ação; nada dele devemos esperar para a leitura do mundo.

Como nada "virá a seu tempo" com o corpo e as experiências de que é capaz, será preciso alguma coisa que "venha de fora" para acrescentar criticidade a ele e ao movimento, "libertando" seu praticante. Esse algo exterior é o "[...] discurso, que pode ter caráter sociológico, antropológico, político, etc. Acopla-se, ao caroço chamado movimento, um invólucro racional na esperança [...] de tornar a aula de Educação Física [...] uma colaboradora num projeto educacional de vanguarda" (GHIRALDELLI JÚNIOR, 1990, p. 197). ${ }^{10}$ Nessas circunstâncias, a disciplina corre o risco de se transformar numa "[...] aula sobre o movimento e não mais uma aula com movimento" (GHIRALDELLI JÚNIOR, 1990, p. 198) ou, como disse Betti (1994), um discurso sobre a cultura corporal de movimento em vez de uma ação pedagógica com ela.

Com essa interpretação, a pedagogia crítica nos levou a crer que todas as nossas experiências (inclusive as corporais) são baseadas em sistemas linguísticos e que não pode haver novas experiências no mundo, mas apenas recombinações de elementos já existentes. Assim procedendo, não problematizou de onde vem uma nova validade de reinvindicações antes de se tornar um discurso racionalizado. Estariam elas, nas palavras de Joas (2002, p. 509), "[...] apenas chegando a mutações ao acaso ou em uma esfera puramente irracional, de modo que sua gênese é completamente irrelevante para a justificação de sua validade?" Ou, então, como no caso da pedagogia crítica marxista, essa nova significação ou reivindicação de validade seria apenas um epifenômeno, cuja base determinante são os movimentos do capital.

A pedagogia crítica, portanto, não se ocupou devidamente da explicação do que Joas (2002) chamou de "problema da articulação". Desconsiderou a tensão entre o dizível e o indizível e/ou o "trânsito" entre aquilo que se passa no âmbito das experiências de que o corpo é capaz e os modos de dizer sobre essas vivências. Na Educação Física brasileira, esse "problema da articulação", precocemente alertado por Ghiraldelli (1990) e Betti (1994), é explícito no neologismo criado por Bracht (1999) ao reivindicar que uma pedagogia crítica da Educação Física não pode ser "movimento sem pensamento", "nem pensamento sem movimento", mas "movimento-pensamento".

10 Ghiraldelli Júnior (1990) estava se referindo à pedagogia marxista da Educação Física. Outras tradições, todavia, padecem do mesmo "construcionismo social do corpo" (ORTEGA, 2008). 
A tematização dessa articulação desafia qualquer discussão a respeito do futuro da pedagogia crítica da Educação Física. ${ }^{11}$ Para ela, a investigação de nossa experiência de articulação, da tensão entre o "que já foi dito" e o que "tem que ser dito", que ainda não foi devidamente articulado, deveria ser crucial. Essa investigação não deve, por um lado, dar um passo atrás na chamada virada linguística, pois é insustentável a existência de uma experiência pura ou de um significado pré-linguístico constituído, uma compreensão do gesto corporal independente da linguagem, como se ele esgotasse todo o seu sentido nos movimentos do corpo e em sua "simbologia". Por outro lado, deve-se evitar o linguicentrismo, que subordina um fundo material sensível pobre, fixado e a-histórico ao círculo mágico da linguagem. É necessário, portanto, preservar as conquistas da virada linguística, mas evitar a visão de um universo linguisticamente fechado que ofereça, só ele, um finito repertório de experiência. É preciso, em outras palavras, "abrir-se ao corpo", "incorporando" a linguagem, mas sem se esquecer de que é a linguagem que institui um quadro que nos permite articular a experiência para a qual encontramos uma articulação inadequada. Sem a linguagem, seria impossível articular os limites de nossas habilidades linguísticas de articular. Nós nem sequer tomamos conhecimento deles. Não é simplesmente uma tensão entre linguagem e intenções disponíveis para falar, mas uma tensão que em si pode ser articulada pela linguagem e tornar-se uma experiência única, pois pode ser articulada (JOAS, 2002).

O significado disponível num determinado jogo linguístico (pensemos, por exemplo, numa prática corporal de movimento) é resultado da sedimentação de tentativas anteriores de articulação. Neste caso, estamos falando da articulação de novos significados e não de uma simples recombinação de determinadas significações instituídas, fato que nos remete, para lembrar de Betti (2007), ao processo do surgimento do novo. O novo significado (pensemos, mais uma vez, no caso de uma prática corporal de movimento) resulta da experiência de uma lacuna, de um silêncio, de um vazio

[...] que incha no já expresso, um vazio que é determinado no sentido de que a pessoa que está prestes a falar sabe que há algo diferente e muito mais a ser dito do que o que já se disse, mas não sabe nada positivo para além desse fato, além do fato de que não é dito com o que já foi dito" (CASTORIADIS, 1984, p.132).

Um silêncio, um não-dito ou um movimento corporal "desconhecido" dos códigos já instituídos, sempre precedem, deste modo, a articulação do novo até que ele faça sentido em uma frase, um tema ou um gesto finalmente encontrado. O papel da articulação consiste precisamente em colmatar a lacuna entre o ainda "não-dito" e o "dito". Quando articulados, damos-Ihes uma forma em que eles podem ser comunicados, discutidos publicamente e racionalizados, por exemplo, por uma pedagogia crítica.

Este processo, segundo Joas (2002), não tem uma direção óbvia. Vamos adiante e para trás entre nossos sentimentos, nossas interpretações e aquelas estabelecidas publicamente. Não há completa coincidência entre esses níveis. Se é difícil ou impossível expressar seus próprios sentimentos no vocabulário disponível em uma determinada cultura, formas inovadoras, em muitos casos metafóricas, são inventadas ou podem ser emprestadas de outras culturas. Assim, devemos falar de uma interação entre a situação vivida, a nossa experiência pré-reflexiva, a nossa articulação individual e o repertório cultural dos padrões

11 Esse desafio, diga-se de passagem, não parece ser apenas a realidade da pedagogia crítica no Brasil, pois é possível notar, no âmbito da literatura "internacional", a necessidade de articular, no seio da pedagogia crítica, a razão com a corporalidade ("incorporando" a subjetividade e as aprendizagens, por assim dizer). Consultar: Tinning (2010), Standal, (2015), Kirk (2020), Moreno, Gómez-Gonzalvo e Toro-Arévalo (2018). 
interpretativos. É neste âmbito que novos significados (novas significações de movimento) podem ser produzidos porque articulados.

Este processo não é exclusivo de gênios, de artistas ou de pessoas especiais, mas a constituição da nova expressão é dependente da criação anônima, diária da qual todos participam e na qual, por meio de constante transformação, a vitalidade da linguagem é preservada. Tratase, neste caso, de um retorno à subjetividade da articulação, vale dizer, à corporeidade do sujeito que age no mundo (JOAS, 2002). Isso porque, de acordo com Joas (2002), a articulação é um caso específico do que ele chamou de "interpretação não-teleológica da intencionalidade da ação" (JOAS, 1996), perspectiva para o qual a intencionalidade não é uma atividade puramente intelectual e não corporal, mas todo e qualquer objetivo deve envolver a corporalidade da ação humana e a criatividade do agente. De acordo com essa visão, a definição de objetivos resulta da reflexão sobre aspirações e tendências pré-reflexivas que sempre têm operado no corpo, mas das quais não temos consciências. A percepção humana, assim, é fundada em nossas disposições em movimentos físicos intencionais, em uma pré-reflexiva intencionalidade do corpo. São as capacidades, os hábitos e os meio de o corpo compreender o meio ambiente que formam o "background" para a intencionalidade. 0 corpo é, deste modo, a estrutura da relação entre o organismo e o meio ambiente, o que é próprio dos seres humanos.

Assim compreendida, cognição, percepção e autorreflexão são como uma fase da ação em que ela é sempre (re)direcionada a um contexto situado, dado que as formas fundamentais da capacidade da ação humana repousam, nas palavras de Joas (1996, p. 158), "[...] no intencional movimento de nosso corpo em conexão com a locomoção, objeto-manipulação e comunicação, nosso mundo é inicialmente estruturado de acordo com essas dimensões". Nesses termos, não há oposição entre a linguagem e o corpo, mas a linguagem é ela própria encarnada, pois concebida como estreitamente associada à ação humana corporal sensível, um saber como fazer vinculado aos contextos dos sujeitos que agem.

Este deveria ser o ponto de partida da pedagogia crítica da Educação Física, quer dizer, não mais um pensamento/discurso sobre o corpo em movimento, mas a ação sensória/ corpórea daqueles que se movimentam. Este é o sentido da incorporação das subjetividades e das experiências nas práticas de aprendizagem que acontecem nas aulas de Educação Física. Seria papel do professor, de um lado, estimular a criação de novas ações corporais desde o sujeito que se movimenta para, assim, abrir/reinventar o plano da cultura corporal de movimento em direções que ainda não foram devidamente articuladas pela linguagem corporal sensível. Em outras palavras, deveria incentivar aquelas experiências de movimento, ainda não articuladas pelas palavras, mas que podem ajudar a conhecer (e transformar) o mundo. Tarefa, decerto, desafiadora. Por outro lado, o professor desempenharia o papel crítico de problematizar a validade normativa dos novos núcleos de sentido assim formados e os já existentes, transformando-os em instrumentos de justiça e do progresso social. Ele estaria preocupado em problematizar se são eles mais "democráticos" e inclusivos, se fomentam afetos de alegria ou tristeza, uma educação repressiva ou sensível, etc.

\section{CONSIDERAÇÕES FINAIS}

Dando sequência a exercícios anteriores no sentido de pensar o "sendo" da pedagogia crítica na Educação Física, oferecemos, neste artigo, uma análise sobre três desafios que 
"comprometem" o debate a respeito do seu futuro. No primeiro deles, discutimos alguns dilemas da crítica na paisagem cognitiva contemporânea, o que tem levado, no plano social, a uma funcionalização do pensamento crítico e, no plano epistemológico, a uma compreensão destranscentalizada da crítica, que resulta na hiperpolitização de sua "qualidade interna". Ainda neste âmbito, problematizamos a pertinência do termo pós-crítico para caracterizar a pluralidade de perspectivas e objetivos que, hoje, configuram a agenda da pedagogia crítica, o que levou à conclusão de que aquela expressão não é a mais adequada para apreendê-la em sua diversidade. Na sequência das análises, apresentamos dois modos (antifundacionista e fundacionista não-representacionista) que justificam uma crítica à sociedade e a suas instituições, oportunidade em que argumentamos em favor de se imputar à pedagogia crítica o posto de "guardiã" da normatividade (e, portanto, de uma dada racionalidade discursiva, epistêmica), mesmo que esse papel traga cada vez mais aborrecimento e seja isento de privilégios epistemológicos. No último tema, especialmente amparados em Hans Joas, analisamos um importante desafio no âmago de várias perspectivas críticas da área, ou seja, a necessidade de pensar os processos de mediação entre o "dizível" e o "indizível", entre razão e emoção, entre "pensamento" e "movimento" na produção do conhecimento em Educação Física, um desafio para o qual colegas têm chamado a atenção desde os anos 1990 e que tem recebido, recentemente, tratamento à luz de referenciais teóricos distintos, como o pragmatismo de Pierce, a "Teoria Crítica" de Adorno e Benjamin, a hermenêutica de Gadamer e a filosofia de Spinoza, Deleuze, Agamben e José Gil. ${ }^{12}$ Apesar disso, ainda há muito para se avançar no entendimento deste "problema da articulação", que tanta importância tem, julgamos, para o futuro do pensamento crítico na área.

\section{REFERÊNCIAS}

ADORNO, Theodor; HORKHEIMER, Max. Dialética do esclarecimento: fragmentos filosóficos. Rio de Janeiro: Jorge Zahar, 1985.

ALMEIDA, Felipe Quintão. Educação física, corpo e epistemologia: uma leitura com o filósofo José Nuno Gil. Atos de Pesquisa em Educação, v. 7, n. 2, p. 329-344, 2012.

BAUMAN, Zygmunt. Modernidade líquida. Rio de Janeiro: Jorge Zahar, 2001.

BETTI, Mauro. O que a semiótica inspira ao ensino da educação física. Discorpo, n. 3, p. 25-45, 1994.

BETTI, Mauro. Corpo, motricidade e cultura: a fundação pedagógica da educação física sob uma perspectiva fenomenológica e semiótica. 2006. Relatório de pesquisa apresentado ao Departamento de Educação Física da Faculdade de Ciências. Bauru, 2006.

BETTI, Mauro. Educação física e cultura corporal de movimento: uma perspectiva fenomenológica e semiótica. Revista da Educação Física, v. 18, n. 2, p. 207-217, 2007.

12 Sugerimos consultar: Betti (1994, 2006), Bracht (2012), Almeida (2012), Fensterseifer e Pich (2012), Pich, Silva e Fensterseifer (2015), 
BRACHT, Valter. Educação física e ciência: cenas de um casamento (in)feliz. ljuí: Unijuí; 1999.

BRACHT, Valter. Corpo, movimento, conhecimento, educação e educação física: uma exploração filosófica. Tese (Pós-Doutorado em Educação) - Universidade Federal de Santa Catarina, 2012.

BRACHT, Valter. Educação Física escolar na América Latina. In: SILVA, Paula Cristina da Costa e Silva et al. Territorialidade e diversidade regional no Brasil e na América Latina: suas conexões com a Educação Física e as Ciências do Esporte. Florianópolis: Tribo da llha; 2016. p. 71-97.

BRACHT, Valter. CBCE "40 anos": sobre "senderos" conflitantes entre epistemología e política. In: LARA, Larissa et al. Ciências do Esporte, Educação Física e produção do conhecimento em 40 anos de CBCE. ljuí: Unijuí, 2019. p. 51-64.

BIESTA, Gert. Say you want a revolution...Suggestions for the impossible future of critical Pedagogy. Educational Theory, v. 49, n. 4, p. 499-510, 1998.

BRUCE, Judy. Dancing on the edge: a self-study exploring postcritical possibilities in Physical Education. Sport, Education and Society, v. 18, n. 6, p. 807-824, 2013.

BRUCE, Judy. On racism and prejudice: exploring post-critical possibilities for service-learning within Physical Education teacher education. Asia-Pacific Journal of Health, Sport and Physical Education, v. 6, n. 3, p. 233-244, 2015.

CASTORIADIS, Cornelius. Crossroads in the labyrinth. Cambridge, MA: MIT Press, 1984.

CORREIA, Elder. Corpo, produção do comum e a potência de movimento: contribuições de Spinoza e Deleuze para o teorizar em Educação Física. 2017. Dissertação (Mestrado em Educação Física) - PPGEF/Universidade Federal do Espírito Santo, Vitória/ES.

COSTA, Marcelo Adolfo Gomes Duque; ALMEIDA, Felipe Quintão de. O corpo intensivo e a Educação Física. Revista Brasileira de Ciências do Esporte, v. 40, n. 1, p. 3-9, 2018.

DEVÍS-DEVÍS, José. Socially critical research perspectives in Physical Education. In: KIRK, D.; MACDONALD, D.; O'SULLIVAN, M. The Handbook of Physical Education. London: SAGE, 2006. p. 37-85.

FENSTERSEIFER, Paulo; PICH, Santiago. Ontologia pós-metafísica e o movimento humano como linguagem. Impulso, v. 22, n. 53, p. 25-36, 2012.

FOUCAULT, Michel. Vigiar e punir: história da violência nas prisões. Rio de Janeiro: Vozes, 1987.

FOUCAULT, Michel. Iluminismo e crítica. Roma: Donzelli Editore, 1999.

GAMBOA, Silvio. O debate da pós-modernidade: as teorias do conhecimento em jogo. Filosofia e Educação: Revista Digital do Paidéia, v. 2, n. 2, p. 74-98, out. 2010.

GHIRALDELLI JÚNIOR, Paulo. Indicações para o estudo do movimento corporal humano da educação física a partir da dialética materialista. Revista brasileira de ciências do esporte, $v$. 11, p. 197-201, 1990.

HONNETH, Axel. Crítica reconstructiva de la sociedad con salvedad genealógica: sobre la idea de "crítica" en la Escuela de Frankfurt. In: HONNETH, Axel. Patologías de la razón: historia y actualidad de la teoría crítica. Buenos Aires: Katz, 2009b. p. 53-63. 
JOAS, Hans. The creativity of action. Chicago: University of Chicago, 1996.

JOAS, Hans. On articulation. Constellations, v. 9, n. 4, p. 506-515, 2002.

KIRK, David. Precarity, critical pedagogy and Physical Education. Abingdon: Routledge, 2020.

LACLAU, Ernesto. Is radical atheism a good name for desconstruction? Diacritics, v. 38, n. 1-2, p. 180-189, 2008.

LOPES, Alice Casimiro. Democracia nas políticas de currículo. Cadernos de Pesquisa, v. 42, p. 700-715, 2012.

LOPES, Alice Casimiro. Teorias pós-críticas, política e currículo. Educação, Sociedade e culturas, n. 39, p. 7-23, 2013.

LOPES, Alice Casimiro. Por um currículo sem fundamentos. Linhas Críticas, v. 21, n. 45, p. 455-466, 2015.

MORENO, Alberto Doña; TORO-ARÉVALO, Sérgio; GÓMEZ-GONZALVO, Fernando. Crítica de la educación física crítica: eurocentrismo pedagógico y limitaciones epistemológicas.

Physchology, Society \& Education, v. 10, n. 3, p. 349-362, 2018.

NIETZSCHE, Friedrich. Crepúsculo dos ídolos: ou como filosofar com o martelo. São Paulo: Companhia das Letras, 2001.

ORTEGA, Francisco. 0 corpo incerto: corporeidade, tecnologias médicas e cultura contemporânea. Rio de Janeiro: Garamond, 2008.

PICH, Santiago; SILVA, Sidinei; FENSTERSEIFER, Paulo Evaldo. Cuerpo lenguage y (bio) política: los giros del cuerpo y su educación en la alta modernidad. In: GALAK, Eduador; GAMBAROTTA, Emiliano. Cuerpo, educación, política: tenciones epistémicas, históricas y práticas. Buenos Aires: Biblos, 2015. p. 59-73.

TINNING, Richard. Pedagogy and human movement: theory, practice, research. New York: Routledge, 2010.

STANDAL, Oyvind. Phenomenology and pedagogy in Physical Education. London: Routledge, 2015.

SILVA, Tomas Tadeu. Documentos de identidade: uma introdução às teorias do currículo. Belo Horizonte: Autêntica, 1999.

TAFFAREL, Celi; ALBUQUERQUE, Joelma. Epistemologias e teorias do conhecimento em educação e educação física: reações aos pós-modernismos. Filosofia e Educação: Revista Digital do Paidéia, Campinas, v. 2, n. 2, p. 8-52, out. 2010.

THIESEN, Juarez da Silva. Virada epistemológica do campo curricular: reflexos nas políticas de currículo e em proposições de interesse privado. In: REUNIÃO ANUAL DA ANPED. 30., 2015. Anais [...]. Florianópolis, ANPEd, 2015. Disponível em: http://37reuniao.anped.org.br/wp-content/ uploads/2015/02/Trabalho-GT12-4018.pdf Acesso em: 20 jun. 2019. 


\section{Apoio:}

presente trabalho foi realizado com apoio da Coordenação de Aperfeiçoamento de Pessoal de Nível Superior - Brasil (CAPES) - Código de Financiamento 001. Processo: 88881.170970/201801. This study was financed in part by the Coordenação de Aperfeiçoamento de Pessoal de Nível Superior - Brasil (CAPES) - Finance Code 001. Process: 88881.170970/2018-01. 